Gordon A. Sutherland MD CH B FFarcs, Joan C. Bevan DROCG FFARCS MD, David R. Bevan MB MRCP FFARCS

\title{
Neuromuscular blockade in infants following intramuscular succinylcholine in two or five per cent concentration
}

This stucty determined the characteristics of the neuro. muscular block which followed intramuscular succinylcholine $4 \mathrm{mg} \cdot \mathrm{kg}^{-1}$ in 20 infants during halothane anaesthesia. The infants were divided into two groups of ten; the first received succinylcholine in two per cent solution and the second in five per cent solution. The mean maximum depression of the first witch of the train-of-four (TI) was $89.7 \pm 5.0$ per cent in $4.0 \pm 0.6 \mathrm{~min}$, and the mean full recovery of $T I$ occurred in $15.6 \pm 0.9$ min after injection. The maximum block achieved and the onset and recovery times were not affected by the concentration used. Depolarizing block, with equal depression of all witches of the train-of-four was observed during the onset of neuromuscular blockade. During recovery, phase II block, as determined by a train-of-four ratio (T4/TI) of 0.5 or less, occurred frequently at $T I$ recovery of $25-50$ per cent, but was not associated with prolonged paralysis. It is concluded that the onset time of $4 \mathrm{~min}$ for intramuscular succinylcholine $4 \mathrm{mg} \cdot \mathrm{kg}^{-1}$ may be too long for emergency use in infants, and no improvement is obtained by increasing the concentration of injected succinylcholine from wo to five per cent.

\section{Key words}

ANAESTHESIA: paediatric, NEUROMUSCULAR RELAXANTS: succinylcholine.

From the McGill Departments of Anaesthesia, Montreal Children's Hospital and Royal Victoria Hospital, Montreal, Quebec.

Address correspondence to: Dr. J.C. Bevan, Department of Anaesthesia, Montreal Children's Hospital, 2300 Tupper Street, Montreal, Quebec, H3H 1 P3.
Intramuscular succinylcholine provides an alternative to intravenous administration in paediatric anaesthesia. However, its usefulness in emergency situations requiring rapid tracheal intubation is limited unless predictable relaxation can be achieved quickly. It has been determined recently in children age one to ten years that a dose of $4 \mathrm{mg} \cdot \mathrm{kg}^{-1}$ is followed by maximum twitch depression of 85-100 per cent in $3.9 \pm 0.5$ min, with recovery after $19.6 \pm 1.7 \mathrm{~min} .^{1}$ If this amount of succinylcholine is given intravenously in incremental doses to adults ${ }^{2,3}$ or by infusion to children ${ }^{4}$ it is associated with the development of phase II neuromuscular block.

Although there are several studies of the effect of intramuscular succinylcholine in children ${ }^{4,5}$ none has investigated the very young in whom intravenous access may be most difficult, and in whom the requirement for succinylcholine, on a weight basis, may be increased. ${ }^{6}$ The purpose of the present study was to determine the efficacy and neuromuscular blocking characteristics of succinylcholine administered to infants in a dose of $4 \mathrm{mg}$ $\mathrm{kg}^{-1}$ intramuscularly, in either a two or five per cent concentration.

\section{Methods}

Following approval by the Hospital Committee on Medical and Dental Evaluation twenty infants born at full term and undergoing a variety of surgical procedures were studied. Their ages ranged from one to seven months and weights from 3.6 to $10 \mathrm{~kg}$. None was known to have any medical condition or 
TABLE I Ages and weights of infants given intramuscular succinylcholine $4 \mathrm{mg} \cdot \mathrm{kg}^{-1}$ in 2 and 5 per cent concentrations

\begin{tabular}{|c|c|c|c|c|c|}
\hline & \multirow[b]{2}{*}{ No. } & \multicolumn{2}{|c|}{ Succinylcholine } & \multirow[b]{2}{*}{$\begin{array}{l}\text { Age in days } \\
\text { (mean } \pm \text { SEM) }\end{array}$} & \multirow[b]{2}{*}{$\begin{array}{l}\text { Wt in } k g \\
(m e a n \pm S E M)\end{array}$} \\
\hline & & $\begin{array}{c}\text { Dose } \\
m g \cdot \mathrm{kg}^{-J}\end{array}$ & $\begin{array}{l}\text { Conc. } \\
\%\end{array}$ & & \\
\hline Group I & 10 & 4 & 2 & $157.6 \pm 23.7$ & $6.3 \pm 0.5$ \\
\hline Group II & 10 & 4 & 5 & $137.6 \pm 21.6$ & $6.5 \pm 0.7$ \\
\hline
\end{tabular}

to be recciving medication which was likely to affect neuromuscular transmission.

Premedication of scopolamine $0.01 \mathrm{mg} \cdot \mathrm{kg}^{-1}$ intramuscularly $1 \mathrm{hr}$ preoperatively was given to those under 6 mos. and pentobarbitol $3 \mathrm{mg} \cdot \mathrm{kg}^{-1}$ rectally $2 \mathrm{hr}$ preoperatively, followed by morphine $0.1 \mathrm{rng} \cdot \mathrm{kg}^{-1}$ with scopolamine $0.01 \mathrm{mg} \cdot \mathrm{kg}^{-1}$ intramuscularly $1 \mathrm{hr}$ later to the others. General anaesthesia was induced by the inhalation of halothane 1-1.5 per cent with 33 per cent oxygen and 66 per cent nitrous oxide. The heart rate was monitored with a precordial stethoscope and electrocardioscope, and blood pressure measured with an oscillotonometer. Neuromuscular transmission was monitored according to the method of Ali et al. ${ }^{\mathrm{B}}$ The ulnar nerve was stimulated supramaximally using skin electrodes applied to the forearm. A Grasis S48 stimulator and SIU5 isolation unit were used to provide trains-of-four with square pulses of $0.2 \mathrm{~ms}$ duration at $2 \mathrm{~Hz}$ frequency and duration $2 \mathrm{~s}$ every $10 \mathrm{~s}$. The hand and forearm were immobilized in a splint and the force of contraction of the adductor pollicis was measured with a Grass FT 03 force-displacement transducer and recorded using a pen-and-ink Grass polygraph recorder.

The patients were randomly divided into two groups of ten patients each. During halothane anaesthesia all received $4 \mathrm{mg} \cdot \mathrm{kg}^{-1}$ succinylcholine by intramuscular injection into the quadriceps femoris muscle after stabilization of the neuromuscular twitch recording. Group I patients were given a two per cent solution and Group $I 1$ patients received a five per cent solution of succinylcholine. Tracheal intubation was attempted when relaxation was maximal. The conditions for intubation were judged to be satisfactory on clinical grounds if the cords were well visualized and abducted and if the procedure was not followed by patient movement.

Monitoring of neuromuscular transmission was conmenced when the patient was anaesthetized, before the injection of succinylcholine. It was continued until recovery from succinylcholine was established i.e. until the first twitch (TI) of the train of four had returned to its control height. The maximum depression of twitch height and times from injection to onset of maximum depression and to return of twitch height to control levels were recorded. The ratio of the height of the fourth to the first twitch in each train-of-four ( $\mathrm{T} 4 / \mathrm{T} 1$ ) was calculated for the control train during halothane anaesthesia and during recovery from succinylcholine at 25,50 and 100 per cent recovery of T1. Phase II block was identified when $\mathrm{T} 4 / \mathrm{T} 1$ was 0.5 or less.

The mean values are presented with the standard error of the mean as the index of dispersion. Student's $t$ test for unpaired data was used where appropriate and the null hypothesis rejected when $p<0.05$.

\section{Results}

There were no significant differences between the ages and weights of the two groups of infants studied (Table I). Six infants were less than three months old (range 44-84 days). There were no significant differences in the maximum twitch depression, times of onset or recovery, or T4/T1 ratio during recovery between these subjects and the remainder. Therefore, they have not been considered as a separate group.

Maximum twitch depression was 85-100 per cent in 80 per cent of the patients, although one in each group achieved only 20-30 per cent. The onset time, from injection to maximum depression of twitch was $4.0 \pm 0.6 \mathrm{~min}$, and tecovery time, from injection to return of twitch to control level, was $15.6 \pm 0.9 \mathrm{~min}$. There were no significant differences in maximum twitch depression or onset and recovery times between the two groups (Table II).

Neuromuscular monitoring showed minimal decrement in T4/T1 of the control train-of-four during 
TABLE II Characteristics of neuromuscular block in infants following intramuscular succinylcholine $4 \mathrm{mg} \cdot \mathrm{kg}^{-1}$

\begin{tabular}{|c|c|c|c|c|c|c|c|}
\hline & \multirow{3}{*}{$\begin{array}{l}\text { Maximum } \\
\text { block } \\
\%\end{array}$} & \multicolumn{2}{|c|}{$\begin{array}{l}\text { Time (min) from } \\
\text { injection to }\end{array}$} & \multirow{3}{*}{$\begin{array}{l}T 4 / T l \\
\text { Conrrol }\end{array}$} & \multirow{2}{*}{\multicolumn{3}{|c|}{$T 4 / T I$ at $T]$ recovery of }} \\
\hline & & \multirow{2}{*}{$\begin{array}{l}\text { Maximum } \\
\text { block }\end{array}$} & \multirow{2}{*}{$\begin{array}{l}100 \% \\
\text { recovery }\end{array}$} & & & & \\
\hline & & & & & $25 \%$ & $50 \%$ & $100 \%$ \\
\hline Group I & $88.6 \pm 7.8$ & $4.3 \pm 0.9$ & $14.5 \pm 1.1$ & $0.99 \pm 0.04$ & $0.70 \pm 0.10$ & $0.77 \pm 0.06$ & $0.91 \pm 0.04$ \\
\hline Group II & $90.8 \pm 6.7$ & $3.8 \pm 0.8$ & $16.8 \pm 1.4$ & $0.99 \pm 0.06$ & $0.54 \pm 0.05$ & $0.62^{*} \pm 0.04$ & $0.82^{*} \pm 0.02$ \\
\hline Groups I and II & $89.7 \pm 5.0$ & $4.0=0.6$ & $15.6 \pm 0.9$ & $0.99 \pm 0.04$ & $0.61 \pm 0.05$ & $0.69 \pm 0.04$ & $0.87 \pm 0.02$ \\
\hline
\end{tabular}

Values are mean \pm SEM.

- Significantly different from Group I, $p<0.05$.

halothane anaesthesia, and intramuscular succinylcholine produced a depolarizing block with equal depression of all four twitches of the train. During recovery from the block, fade in the train-of-four was seen. This was most marked at $25-50$ per cent recovery of $\mathrm{T} 1$, but $\mathrm{T} 4 \mathrm{~T} 1$ values remained low at 100 per cent recovery of $\mathrm{T} 1$ (Table II). Phase II block, defined by T4/T1 of 0.5 or less was evident in 35 per cent of patients, two in Group $I$ and five in Group II, at 25 per cent recovery of $\mathrm{T} 1$.

Following the administration of intramuscular succinylcholine, no clinically significant changes in heart rate, rhythm or blood pressure occurred. In all cases the conditions for intubation were satisfactory and tracheal intubation was achieved without difficulty at the first attempt.

\section{Discussion}

In these infants anaesthetized with 1-1.5 per cent halothane, intramuscular succinylcholine in the dose of $4 \mathrm{mg} \cdot \mathrm{kg}^{-1}$ recommended for older children by Liu et al., ${ }^{1}$ resulted in satisfactory intubating conditions in all the patients studied. None showed significant cardiovascular changes, which is in agreement with Mazze and Dunbar's observations with intramuscular succinylcholine in children. ${ }^{9}$ No signs of pulmonary oedema were seen in these anaesthetized patients, although it has been suggested that it is causally related to the use of intramuscular succinylcholine in conscious neonates and infants. ${ }^{10}$

In comparison with the older children studied by Liu et al., ${ }^{1}$ the maximum depression of twitch height observed was more variable, but of similar magnitude. Whilst most of the patients had 85-100 per cent depression of twitch, two achieved less than 30 per cent depression, although it is possible that these may have resulted from inadvertent subcutaneous injection. However, airway control was obtained before the onset of complete neuromuscular block, allowing intubation even in these two cases. Of more importance is the dose-time relationship of an effective dose of intramuscular succinylcholine. The mean onset time to maximal twitch depression was $4.0 \pm 0.6 \mathrm{~min}$ in infants compared with $3.9 \pm 0.5 \mathrm{~min}$ in older children.' Recovery time, from injection to return of $\mathrm{T} 1$ to control was $15.6 \pm 0.9$ min compared with $19.6 \pm$ $1.7 \mathrm{~min} .{ }^{\prime}$ The similarity in these results can be largely explained by the pharmacokinetic behaviour of ionized neuromuscular blocking drugs in infants. The volume of distribution, ${ }^{1,12}$ largely extracellular fluid, ${ }^{7}$ is increased, so that the intensity and duration of action should be decreased compared with older children when succinylcholine is administered on a weight basis. However, the increased cardiac output ${ }^{13}$ and rapid circulation time of infants ${ }^{14}$ conceal this onset data, and the decreases in plasma cholinesterase and plasma clearance ${ }^{11,12}$ tend to increase the duration of action. Thus, there was little difference in the pharmacodynamic behaviour of succinylcholine between infants and children after a dose of $4 \mathrm{mg} \cdot \mathrm{kg}^{-1}$ intramuscularly.

The usefulness of intramuscular succinylcholine would be greatly increased if the onset time could be shortened. Factors concemed in the absorption of the drug must be important determinants in the time course of the drug action. Increasing the area of absorbing surface should increase the rate of absorption, but Liu et al.' found no difference in the onset time when they divided the succinylcholine dose into two intramuscular injections. It has also been suggested that higher concentrations of an 
injected drug would be absorbed more rapidly, ${ }^{15}$ but we obtained no improvement in onset time with a five per cent solution and the recovery times were also similar with two and five per cent solutions. This result is paralleled by findings with lidocaine, which is chemically similar to succinylcholine in structure and metabolism, but because its hydrolysis by plasmacholinesterase is slower, its pharmacokinetic behaviour can be determined more easily. It has been established that the plasma concentration of lidocaine after intramuscular injection is related to the total dose administered and not to the concentration of the injected solution. ${ }^{16,17}$

The pattern of neuromuscular blockade during the onset of block in the infants was of the depolarizing type with depression, and later recovery, of $\mathrm{T} 1{ }^{18}$ However, train-of-four fade was demonstrated in all of the patients to a certain extent. In a quarter there was some fade of the control train during halothane anaesthesia. During recovery marked fade occurred, with mean $T 4 / \mathrm{T} 1$ of 0.61 at 25 per cent recovery of $T 1$ and 0.69 at 50 per cent recovery of T1. After full recovery of T1, 75 per cent of patients still showed a degree of fade, with a mean T4/T1 of 0.87 . Phase II block, as defined by a T4/T1 value of 0.5 or less, was observed in seven of the 20 patients at 25 per cent recovery of $\mathrm{T} 1$, with five of these in the group receiving the five per cent solution. However, this appearance of phase II block was not considered to be clinically important as it was not associated with prolonged neuromuscular blockade.

In conclusion, intramuscular succinylcholine in a dose of $4 \mathrm{mg} \cdot \mathrm{kg}^{-1}$ produces a similar pattem of neuromuscular block as previously described in older children. The phase II characteristics of the block, although frequent, are not accompanied by prolonged paralysis. The onset time of $4.0 \pm 0.6$ min may be too long for emergency situations, but there is no advantage from using a concentrated, five per cent, solution compared with two per cent.

\section{Acknowledgements}

We wish to thank the surgeons and operating room personnel of the Montreal Children's Hospital for their co-operation in monitoring these patients and Mrs. P. Gowan for her secretarial assistance. This is publication number 83013 of the McGill University-Montreal Children's Hospital Research Institute.

\section{References}

1 Liu LMP, De Cook TH, Goudsouzian NG, Ryan JF, Liu PL. Dose response to intramuscular succinylcholine in children. Anesthesiology 1981; 55: 599602.

2 Hilgenberg JC, Stoelting RK. Characteristics of succinylcholine-produced phase II neuromuscular block during enflurane, halothane, and fentanyl anaesthesia. Anesth Analg 1981; 60; 192-6.

3 Donati $F$, Bevan $D R$. Effect of enflurane and fentanyl on the clinical characteristics of longterm succinylcholine infusion. Can Anaesth Soc J 1982; 29: 59-64.

4 De Cook TH, Goudsouzian NG. Tachyphylaxis and phase II block development during infusion of succinylcholine in children. Anesth Analg 1980; 59: 639-43.

5 Beldavs $J$. Intramuscular succinylcholine for endotracheal intubation in infants and children I. Can Anaesth Soc I 1959; 6: 141-7.

6 Beldavs $J$. Intramuscular succinylcholine for endotracheal intubation in infants and children II. Can Anaesth Soc J 1962; 9: 306-11.

7 Cook $D R$. Muscle relaxants in infants and children. Anesth Analg 1981; 5: 335-43.

8 Ali $H H$, Utting $J E, G r a y C$. Stimulus frequency in the detection of neuromuscular block in humans. Br J Anaesth 1970; 42: 967-77.

9 Mazze RI, Dunbar RW. Intralingual succinylcholine administration in children: an alternative to intravenous and intramuscular routes? Anesth Analg 1968; 47: 605-15.

10 Cook DR, Westman HR, Rosenfeld L, Hendershot $R J$. Pulmonary edema in infants: possible association with intramuscular succinylcholine. Anesth Analg 1981; 60: 220-3.

11 Fisher DM, O'Keeffe C, Stanski DR, Cronnelly $R$, Miller RD, Gregory GA. Pharmacokinetics and pharmacodynamics of d-rubocurarine in infants, children and adults. Anesthesiology 1982; 57: 203-8.

12 Matteo PS, MCDaniel DD, Lieberman IG, Salantire E, Diaz J. Pharmacokinetics of d-tubocurarine in neonates, infants and children. Anesthesiology 1982; 57: A269.

13 Gregory GA. Pediatric Anesthesia: in Anesthesia, ed Miller RD, New York, Edinburgh, London, Melbourne: Churchill Livingstone 1981; 1197-1229.

14 Zideman DA, Rimmer MA, Williams WG, Steward DJ. Thermodilution cardiac output de- 
terminations in small infants: some problems and their solutions. Anesthesiology 1979; 51: S320.

15 Goodman AG, Goodman $L S$, Gilman $A$. The pharmacological Basis of Therapeutics. 6th. ed. New York: Macmillan Publishing Co. Inc, 1980; 5.

16 Jebson $P$. Intramuscular lignocaine $2 \%$ and $10 \%$. Br Med J 1971; 3: 566-7.

17 Scott $D B$, Jebson PJR, Braid DP, Ortengren $B$, Frisch $P$. Factors affecting plasma levels of lignocaine and prilocaine. Br J Anaesth 1972; 44: 1040-9.

18 Durant NN, Katz RL. Suxamethonium. Br J Anaesth 1982: 54: 195-208.

\section{Résumé}

Cette étude détermine les caractéristiques du bloc neuromusculaire obtenu par l'injection intra-musculaire de succinylcholine $4 \mathrm{mg}^{\cdot \mathrm{kg}^{-1}}$ chez 20 enfants préalablement anesthésiés à l'halothane. Ceux-ci ont été répartis en deux groupes égaux pour comparer les effets de solutions à deur et cinq pour cent de succinylcholine. La diminution maximale moyenne de l'amplitude de la première contraction (T1) provoquée par une volée de quatre stimulations a été de $89.7 \pm 5$ pour cent en $4.0 \pm 0.6$ min et le temps moyen de récupération complète de l'amplitude de $T 1$ a été de $15.6 \pm 0.9 \mathrm{~min}$. L'intensité ainsi que les temps $d$ 'installation et de recouvrance du bloc étaient inde. pendants de la concentration utilisée. Un bloc de type dépolarisant, avec une dimintion bgale de toutes les contractions élicitées par la volée de quatre, a été observé durant l'installation du bloc neuro-musculaire. Durant la période de recouvrance, un bloc de phase II tel que déterminé par un rapport d' amplitudes $T 4 / T 1$ de 0.5 ou moins a été observé fréquemment au moment où la recouvrance de Tl était aux alentours de 25-50 pour cent mais ne fut pas suivi de curarisation prolongée. On en conclut qu' un temps d'installation de quatre minutes pour une injection intramusculaire de succinylcholine $4 \mathrm{mg} \cdot \mathrm{kg}^{-1}$ est trop lent pour permettre l'utilisation de ce mode de curarisation dans les cas d'urgence chez les enfants. De plus, aucune amélioration n'est obtenue en augmentant la concentration de la succinylcholine injectée de deux à cinq pour cent. 